OPEN ACCESS

Edited by:

Ronald H. M. A. Bartels, Radboud University Nijmegen Medical Center, Netherlands

Reviewed by:

Sanjeev Kumar Bhoi,

All India Institute of Medical Sciences Bhubaneswar, India Andrew C. Smith, Regis University, United States

*Correspondence: Abdu Kisekka Musubire amusubire@yahoo.com

Specialty section:

This article was submitted to Spinal Cord Medicine,

a section of the journal

Frontiers in Neurology

Received: 20 August 2016 Accepted: 06 November 2017 Published: 08 December 2017

Citation:

Musubire AK, Meya DB, Bohjanen PR, Katabira ET, Barasukana P, Boulware DR and Meyer A-C (2017) A Systematic Review of Non-Traumatic Spinal Cord Injuries in Sub-Saharan Africa

and a Proposed Diagnostic Algorithm for Resource-Limited

Settings.

Front. Neurol. 8:618

doi: 10.3389/fneur.2017.00618

\section{A Systematic Review of Non-Traumatic Spinal Cord Injuries in Sub-Saharan Africa and a Proposed Diagnostic Algorithm for Resource-Limited Settings}

\author{
Abdu Kisekka Musubire ${ }^{1,2 *}$, David B. Meya ${ }^{1,3}$, Paul R. Bohjanen ${ }^{4}$, Elly Tebasooke Katabira ${ }^{3}$, \\ Patrice Barasukana ${ }^{5}$, David R. Boulware ${ }^{4}$ and Ana-Claire Meyer ${ }^{6}$ \\ ${ }^{1}$ College of Health Sciences, Infectious Disease Institute, Makerere University, Mulago Hospital Complex, Kampala, Uganda, \\ ${ }^{2}$ Medicine, Mulago National Referral Hospital, Mulago Hospital Complex, Kampala, Uganda, ${ }^{3}$ Medicine, College of Health \\ Sciences, Makerere University, Mulago Hospital Complex, Kampala, Uganda, ${ }^{4}$ Division of Infectious Diseases and \\ International Medicine, Medicine, University of Minnesota, Minneapolis, MN, United States, ${ }^{5}$ Neurology, University Teaching \\ Hospital of Kamenge, Bujumbura, Burundi, ${ }^{6}$ Neurology, Yale University, New Haven, CT, United States
}

Background: Non-traumatic myelopathy is common in Africa and there are geographic differences in etiology. Clinical management is challenging due to the broad differential diagnosis and the lack of diagnostics. The objective of this systematic review is to determine the most common etiologies of non-traumatic myelopathy in sub-Saharan Africa to inform a regionally appropriate diagnostic algorithm.

Methods: We conducted a systemic review searching Medline and Embase databases using the following search terms: "Non traumatic spinal cord injury" or "myelopathy" with limitations to epidemiology or etiologies and Sub-Saharan Africa. We described the frequencies of the different etiologies and proposed a diagnostic algorithm based on the most common diagnoses.

Results: We identified 19 studies all performed at tertiary institutions; 15 were retrospective and 13 were published in the era of the HIV epidemic. Compressive bone lesions accounted for more than $48 \%$ of the cases; a majority were Pott's disease and metastatic disease. No diagnosis was identified in up to $30 \%$ of cases in most studies; in particular, definitive diagnoses of non-compressive lesions were rare and a majority were clinical diagnoses of transverse myelitis and HIV myelopathy. Age and HIV were major determinants of etiology.

Conclusion: Compressive myelopathies represent a majority of non-traumatic myelopathies in sub-Saharan Africa, and most were due to Pott's disease. Non-compressive myelopathies have not been well defined and need further research in Africa. We recommend a standardized approach to management of non-traumatic myelopathy focused on identifying treatable conditions with tests widely available in low-resource settings.

Keywords: non-traumatic, spinal cord injury, myelopathy, sub-Saharan Africa, paraplegia 


\section{BACKGROUND}

Non-traumatic myelopathy is a challenging condition to manage because of the wide differential diagnosis and substantial regional variation $(1,2)$. This condition is thought to be more common in Africa than in Europe (3). In Sub-Saharan Africa, non-traumatic myelopathy is associated with a high morbidity (about 50\% persistent disability) and mortality (around 10\% in admission) and has important economic repercussions for patients and health systems (4-7).

Advanced diagnostics, such as the magnetic resonance imaging (MRI) and several cerebrospinal fluid (CSF) studies, are not readily available in many settings in Sub-Saharan Africa. Thus, standard of care diagnostic approaches for the evaluation of patients presenting with non-traumatic myelopathy developed in resource-rich settings are not applicable to primary care settings in sub-Saharan Africa. Recent reviews of spinal cord injury have focused on descriptive epidemiology and have not been structured so that they can inform a diagnostic approach to non-traumatic myelopathy $(1,2)$. The objectives of this review were to describe the causes of non-traumatic myelopathy from sub-Saharan Africa and develop an evidence-based diagnostic algorithm for the evaluation of patients that present with nontraumatic myelopathy in resource-limited settings.

\section{METHODS}

We conducted a systematic review designed to identify studies describing the epidemiology of non-traumatic spinal cord injury/myelopathy in Sub-Saharan Africa (8). We searched the Medline and Embase database using Ovid to identify peer-reviewed manuscripts describing the epidemiology and etiology of non-traumatic spinal cord injury, myelopathy, paraplegia, and quadriplegia in a general outpatient or inpatient clinical population. Search terms were: 1. paraplegia.mp; 2. quadriplegia.mp; 3. myelopa ${ }^{\star} . \mathrm{mp} ; 4$. spinal cord.ab; 5. spinal cord.mp; 6. (1 or 2 or 3 or 4 or 5); 7. exp Africa/; 8. (6 and 7); 9. polio.mp; and 10. (8 not 9). Records were then reviewed for inclusion/exclusion based on title, then abstract, and then full-text. Inclusion criteria were as follows: (i) study conducted in Africa, (ii) published before 1 January 2015, (iii) reports more than one etiologic agent, and (iv) described the etiology of non-traumatic myelopathy in a general clinical population by disease process. Exclusion criteria were as follows: (i) study only included children $<12$ years of age, (ii) could not calculate the frequency of each etiology with data provided in the manuscript, (iii) study included less than 30 individuals, (iv) sample identified from a record review of imaging studies, or (v) studies exclusively focused on radiological or anatomical terminology, and (vi) study conducted outside Sub-Saharan Africa. Two authors (Abdu Kisekka Musubire and Ana-Claire Meyer) independently reviewed the list of titles and abstracts and selected manuscripts for inclusion. Any discrepancies were discussed until consensus was reached. Data on clinical setting, study methods, diagnostic investigations, and frequencies of etiologies were abstracted from the manuscripts (Abdu Kisekka Musubire).

\section{Statistical Analysis}

We described the proportion of etiologies of non-traumatic myelopathy and summary averages were calculated from the weighted mean with $95 \%$ confidence interval $(95 \% \mathrm{CI})$. We excluded polio infection, trauma, somatoform disorders, or diagnosis not localizing to the spinal cord and roots.

Subsequently, a diagnostic algorithm was generated focusing on identifying the most common treatable causes in this region. Other considerations were efficient triage of patients that should be treated by other clinical services such as neurosurgery or orthopedics and the cost and availability of diagnostic tests in typical sub-Saharan African hospitals.

\section{RESULTS}

We identified 19 studies (Figure 1) that met our selection criteria. These studies were primarily retrospective, occurred over a large time span (1970-2010) and were conducted predominantly in inpatient tertiary centers in variety of settings including medical, neurological, and neurosurgical wards (Table 1). Only 10 of the 54 countries that comprise the African continent were represented. Most of the studies were done in the West African region (9/19), followed by the East African region (8/19) and only two studies from the South African region. Most of the studies were retrospective (15/19) case series. Only 5 studies specifically focused on myelopathy with the majority covering paraplegia/ paraparesis. Several studies (6/19) had less than 100 participants.

Among individuals presenting with non-traumatic myelopathy, there was male preponderance and the average age at presentation increased over time, from an average age in the third decade in the 1970s $(11,12)$ to the fourth decade in the $1990 \mathrm{~s}$ and 2000s $(7,16)$. HIV-infected individuals with non-traumatic myelopathy were younger than HIV-negative patients $(22,23)$. More than $80 \%$ initially presented with paraplegia/paresis $(14,22)$, and more than $40 \%$ presented with a complete transverse myelopathy (involvement of the motor, sensory, and autonomic dysfunction) $(3,22)$.

There was a striking delay from symptom onset to presentation for clinical care in most studies; for example, only $53-68 \%$ of patients in South Africa presented within 6 weeks of onset (22). In Tanzania, the mean delay was 8 weeks (12), while in Nigeria and Ethiopia approximately $50 \%$ of the patients presented between 8 and 16 weeks after symptom onset $(4,7,9)$.

\section{Diagnostic Approach}

In general, the diagnostic approach within each study was not uniform and there were few diagnostics available. Thus, most diagnoses were presumptive or based on clinical criteria (Table 2). Plain radiographs of the spine were used in nearly all studies and were helpful in diagnosing tuberculous osteomyelitis of the vertebrae, or Pott's disease, and malignancies that cause compressive bone lesions. In a few recent studies, advanced imaging was used; three studies documented the use of CT and five studies an MRI. However, even when CT or MRI was used in a study, only a small proportion of patients were able to access these modalities. This is likely because most studies were derived 


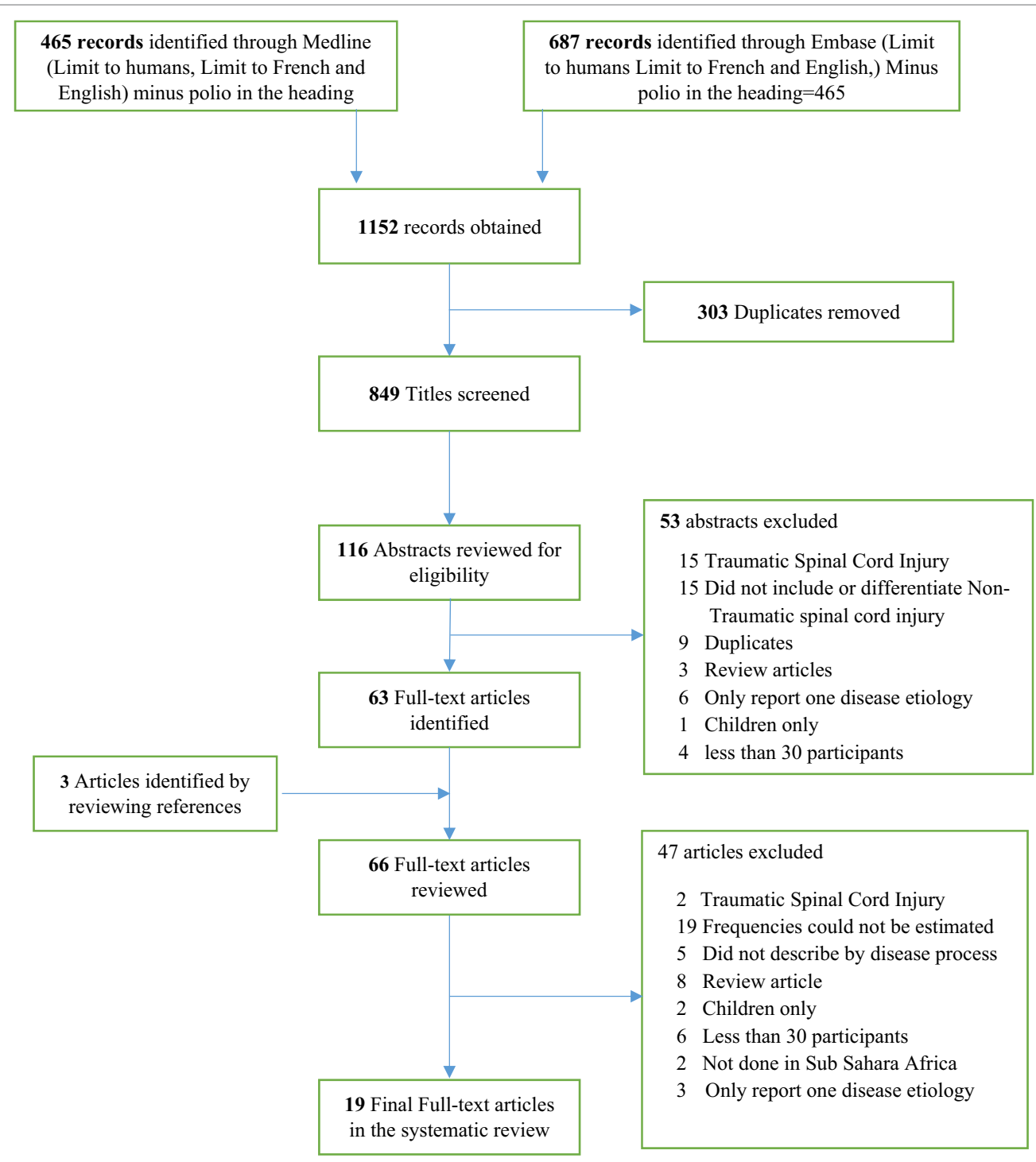

FIGURE 1 | Search strategy in Medline and Embase using OVID search strategy. Flow diagram of the Search strategy through OVID in both the Medline and Embase database going through the selection criteria.

from retrospective clinical case series where the costs of advanced imaging are borne by the patient and, thus, only those able to afford the study are able to obtain them.

Cerebrospinal fluid microscopy was commonly employed, though only two studies from South Africa were able to perform more comprehensive evaluations for infections, including microbial cultures or polymerase chain reaction (PCR) testing. A few studies did stool and urinalysis in search of schistosomiasis. Several studies from neurosurgical units had histological diagnoses, as they were drawn from samples of surgical cases with biopsies.

\section{Etiology}

Our initial approach to categorizing etiologies of non-traumatic spinal cord injury/myelopathy was drawn from consensus guidelines published by the International Spinal Cord Injury
(ISCI) group (24). However, the ISCI approach relies heavily on MRI that was not generally available in the studies we reviewed. Thus, we adapted the ISCI approach for a sub-Saharan African setting as follows. The diagnoses were initially grouped into three broad categories: extramedullary or compressive, intramedullary or non-compressive, and unclear etiology (Table 3). We then categorized extramedullary or compressive lesions into bone or non-bone compressive lesions on the basis of plain radiographs of the spine, myelogram, and the stated diagnosis in the reviewed publication. Finally, we identified etiologies of intramedullary or non-compressive lesions based on laboratory evaluation.

In total, we found over 200 different etiologies described in the included studies (Appendix S1 in Supplementary Material) though this was dependent on the availability of diagnostics. The different etiologies were then grouped in different categories 
TABLE 1 | Study methodology: non-traumatic spinal cord injury.

\begin{tabular}{|c|c|c|c|c|c|c|c|c|c|c|}
\hline \multirow[b]{2}{*}{ Reference } & \multicolumn{2}{|c|}{ Article overview } & \multirow[b]{2}{*}{ Study setting } & \multirow[b]{2}{*}{ Study design } & \multirow[b]{2}{*}{ Study population } & \multirow[b]{2}{*}{$N$} & \multicolumn{2}{|c|}{ Demographics } & \multicolumn{2}{|c|}{ Presentation } \\
\hline & Study period & Country & & & & & Age & Sex (\% male) & Paraplegia (\%) & Time (weeks) \\
\hline Zenebe (4) & 1990-1993 & Ethiopia & Medical Wards & Retrospective & Myelopathies & 130 & $40(13-69)$ & 64 & 77 & - \\
\hline Zenebe et al. (9) & 1981-1988 & Ethiopia & Internal Medicine Ward & Retrospective & Paraplegia/Paraparesis & 164 & $36(15-70)$ & 63 & 100 & 8 \\
\hline Brown (3) & 1972-1975 & Malawi & Medical Wards & Prospective & Paraplegia/Paraparesis & 102 & $15^{\mathrm{b}}$ & 69 & 100 & $52^{c}$ \\
\hline Naus et al. (10) & 2000-2002 & Malawi & Medical Wards & Prospective & Myelopathy & 33 & $34(9-67)$ & 73 & - & - \\
\hline Leigh (11) & 1975-1976 & Tanzania & Medical Wards & Retrospective & Myelopathies & 90 & $36(3-80)$ & 68 & $82^{\mathrm{a}}$ & - \\
\hline Scrimgeour (12) & 1972-1979 & Tanzania & Medical Wards & Retrospective & Paraplegia/Paraparesis & 100 & $31(2-80)$ & 67 & 100 & 10 \\
\hline Parry et al. (5) & 1989-1994 & Zimbabwe & Rehabilitation Centre & Retrospective & Paraplegia/Paraparesis & 159 & $(-) 6-80$ & 54 & 100 & - \\
\hline Mahomed and Gelfand (13) & 1972-1973 & Zimbabwe & General Ward & Retrospective & Paraplegia/Paraparesis & 100 & $30(4-80)$ & 65 & 100 & - \\
\hline Looti et al. (14) & 1999-2006 & Cameroon & Neurology/Neurosurgery & Retrospective & Myelopathies & 147 & $45(1.6)$ & 59 & 84 & 2 \\
\hline Nyame (15) & 1991-1994 & Ghana & Medical Wards & Prospective & Paraplegia/Paraparesis & 64 & $40(15-82)$ & 59 & $88^{a}$ & - \\
\hline Owolabi et al. (7) & 2006-2009 & Nigeria & Medical Wards & Retrospective & Paraplegia/Paraparesis & 98 & $40(15)$ & 72 & 100 & $8 \sim$ \\
\hline Ogunniyi et al. (16) & 1988-1993 & Nigeria & Neurology/Neurosurgery & Retrospective & Spinal Cord Diseases & 104 & $45(16)$ & 77 & 70 & 47 \\
\hline Osuntokun (17) & 1957-1969 & Nigeria & Neurology/Neurosurgery & Retrospective & Neurology patients & 9,600 & - & - & - & - \\
\hline Jacquin-Cotton et al. (18) & 1960-1969 & Senegal & Neuropsychiatric Hospital & Retrospective & Paraplegia & 457 & - & - & 100 & - \\
\hline Ndiaye et al. (19) & 1972-1987 & Senegal & Neurology/Neurosurgery & Retrospective & Compressive Lesions & 253 & $40-50$ & d & - & - \\
\hline Kassegne et al. (20) & 1998-2007 & Togo & Neurology ward & Retrospective & Spinal Cord Compression & 39 & $53(22-79)$ & 77 & - & 15 \\
\hline Balogou et al. (21) & 1995-1999 & Togo & Campus Teaching Hospital & Retrospective & Paraplegia/Paraparesis & 243 & $38(10-75)$ & 56 & - & - \\
\hline \multirow[t]{3}{*}{ Modi et al. (22) } & $\sim 2010$ & $\begin{array}{l}\text { South } \\
\text { Africa }\end{array}$ & Neurology/Neurosurgery & Prospective & Myelopathies & 100 & & & & $6^{e}$ \\
\hline & & & & & HIV positive & 50 & $35(8.6)$ & 50 & 96 & - \\
\hline & & & & & HIV negative & 50 & $53(15.2)$ & 66 & 87 & - \\
\hline Bhigjee et al. (23) & $\sim 2000$ & $\begin{array}{l}\text { South } \\
\text { Africa }\end{array}$ & Neurology Wards & Prospective & HIV positive with myelopathy & 33 & 39.8 & 39 & - & - \\
\hline
\end{tabular}

Countries have been group by geographical region and in alphabetical order, paraplegias are presented as a proportion of paraplegia and quadriplegias, age is presented as mean (SD) or median (range), and time is presented as average time to presentation in weeks.

aDerived from cases of cervicle spondylosis.

${ }^{\circ} \mathrm{Age}(73.5 \%$ of the participants more than 15 years).

'84\% of the patients presented within 52 weeks. $55 \%$ of the participants presented within 8 weeks.

¿Study stated male predominant.

${ }^{5} 53 \%$ HIV-positive and $68 \%$ HIV-negative patients presented in less than 6 weeks. 
TABLE 2 | Diagnostics utilized systematically in the studies on Non-Traumatic Myelopathy in Africa.

\begin{tabular}{|c|c|c|c|c|c|c|c|c|c|c|c|c|}
\hline Reference & Country & $\begin{array}{l}\text { Spinal } \\
\text { X-ray }\end{array}$ & Myelography & $\begin{array}{c}\text { CT/CT } \\
\text { myelography }\end{array}$ & MRI & $\begin{array}{c}\text { Tissue } \\
\text { histology }\end{array}$ & $\begin{array}{c}\text { CSF } \\
\text { microscopy }\end{array}$ & $\begin{array}{c}\text { Full blood } \\
\text { count }\end{array}$ & $\begin{array}{l}\text { Serum } \\
\text { VDRL }\end{array}$ & ESR & $\begin{array}{l}\text { HIV } \\
\text { Ab }\end{array}$ & $\begin{array}{c}\text { Stool } \\
\text { microscopy }\end{array}$ \\
\hline Zenebe (4) & Ethiopia & $x$ & $x$ & - & - & $x$ & $x$ & - & - & $x$ & $x$ & - \\
\hline Zenebe et al. (9) & Ethiopia & $x$ & $6 \%$ & - & - & $67 \%$ & $x$ & - & - & - & - & - \\
\hline Brown (3) & Malawi & $x$ & $x$ & - & - & $x$ & $x$ & $x$ & - & $x$ & - & $x$ \\
\hline Naus et al. (10) & Malawi & - & - & - & - & - & - & - & - & - & - & - \\
\hline Leigh (11) & Tanzania & $x$ & $48 \%$ & - & - & $21 \%$ & $x$ & $x$ & - & - & - & - \\
\hline Scrimgeour (12) & Tanzania & $88 \%$ & $41 \%$ & - & - & Variable & $62 \%$ & $X$ & $X$ & $x$ & - & $x$ \\
\hline Parry et al. (5) & Zimbabwe & $x$ & $x$ & - & - & x & x & $x$ & - & - & - & - \\
\hline $\begin{array}{l}\text { Mahomed and } \\
\text { Gelfand (13) }\end{array}$ & Zimbabwe & $x$ & $x$ & - & - & $x$ & $x$ & - & - & - & - & - \\
\hline Looti et al. (14) & Cameroon & $x$ & $39 \%$ & $48 \%$ & - & $x$ & $x$ & $x$ & - & - & $x$ & - \\
\hline Nyame (15) & Ghana & $x$ & $x$ & - & - & $67 \%$ & $x$ & $x$ & $x$ & $x$ & - & $x$ \\
\hline Owolabi et al. (7) & Nigeria & $x$ & - & - & $26 \%$ & - & $x$ & $x$ & $x$ & $x$ & $82 \%$ & - \\
\hline Ogunniyi et al. (16) & Nigeria & $x$ & $x$ & $6 \%$ & $4 \%$ & Rarely & $x$ & $x$ & - & $x$ & - & - \\
\hline Osuntokun (17) & Nigeria & - & - & - & - & - & - & - & - & - & - & - \\
\hline $\begin{array}{l}\text { Jacquin-Cotton } \\
\text { et al. (18) }\end{array}$ & Senegal & $x$ & $x$ & - & - & $x$ & $x$ & $x$ & - & - & - & - \\
\hline Ndiaye et al. (19) & Senegal & $x$ & $X$ & - & - & $x$ & $x$ & $x$ & - & - & - & - \\
\hline Kassegne et al. (20) & Togo & $x$ & $5 \%$ & $90 \%$ & $5 \%$ & - & - & - & - & - & - & - \\
\hline Balogou et al. (21) & Togo & $x$ & $37 \%$ & - & - & - & 227 & $x$ & - & - & - & - \\
\hline Modi et al. (22) & South Africa & $x$ & - & - & $x$ & $x$ & $x^{a}$ & $x$ & $x$ & $x$ & $x$ & - \\
\hline Bhigjee et al. (23) & South Africa & - & - & - & $x$ & - & $X^{a}$ & $x$ & $x$ & - & $x$ & - \\
\hline
\end{tabular}

aOnly two studies extended CSF analysis for autoimmune and infectious causes (22, 23). Three studies performed CSF bacterial cultures (11, 22, 23). Three studies performed HTLV antibody testing $(14,21,23)$. Chest X-rays were routinely done in five studies (4, 9, 12, 15, 22). Serum biochemistry was declared done in five studies (5, 7, 11, 15, 22). VDRL, Venereal Disease Research Laboratory test; ESR, Erythrocyte Sedimentation Rate; HIV abs, HIV antibody assays; CSF, Cerebral spinal fluid; MRI, magnetic resonance imaging; CT, computed tomography. X means test done in all patients, - means test was not declared done in the methodology. Tissue histology by Biopsy.

TABLE 3 | Common diagnosis according to classification of the causes of Non-traumatic spinal cord injury in Sub-Saharan Africa.

\begin{tabular}{|c|c|c|c|c|c|c|c|}
\hline Reference & Country & $\begin{array}{l}\text { African } \\
\text { region }\end{array}$ & Number & $\begin{array}{l}\text { Myelopathy } \\
\text { number }\left(N^{\mathrm{a}}\right)\end{array}$ & $\begin{array}{c}\text { Extramedullary } \\
\text { myelopathy }\end{array}$ & $\begin{array}{l}\text { Intramedullary } \\
\text { myelopathy }\end{array}$ & Unclear etiology \\
\hline Zenebe (4) & Ethiopia & Eastern & 130 & 130 & $76(58 \%)$ & 54 (42\%) & $0(0 \%)$ \\
\hline Zenebe et al. (9) & Ethiopia & Eastern & 164 & 142 & $110(77 \%)$ & 32 (23\%) & $0(0 \%)$ \\
\hline Brown (3) & Malawi & Eastern & 102 & 94 & 68 (72\%) & $23(24 \%)$ & $3(3 \%)$ \\
\hline Naus et al. (10) & Malawi & Eastern & 33 & 26 & $3(12 \%)$ & $23(88 \%)$ & $0(0 \%)$ \\
\hline Leigh (11) & Tanzania & Eastern & 90 & 90 & $48(53 \%)$ & $18(20 \%)$ & $24(27 \%)$ \\
\hline Scrimgeour (12) & Tanzania & Eastern & 100 & 96 & 69 (72\%) & 15 (16\%) & $12(13 \%)$ \\
\hline Parry et al. (5) & Zimbabwe & Eastern & 159 & 148 & 105 (71\%) & $31(21 \%)$ & $12(8 \%)$ \\
\hline Mahomed and Gelfand (13) & Zimbabwe & Eastern & 100 & 65 & 44 (68\%) & $21(32 \%)$ & $0(0 \%)$ \\
\hline Looti et al. (14) & Cameroon & Western & 147 & 147 & $98(67 \%)$ & $18(12 \%)$ & $31(21 \%)$ \\
\hline Nyame (15) & Ghana & Western & 64 & 55 & $39(71 \%)$ & $11(20 \%)$ & $5(9 \%)$ \\
\hline Owolabi et al. (7) & Nigeria & Western & 98 & 85 & 52 (61\%) & $19(22 \%)$ & $14(16 \%)$ \\
\hline Ogunniyi et al. (16) & Nigeria & Western & 108 & 108 & $73(68 \%)$ & 31 (29\%) & $4(4 \%)$ \\
\hline Osuntokun (17) & Nigeria & Western & 9,600 & 1,536 & 750 (49\%) & 707 (46\%) & $79(5 \%)$ \\
\hline Jacquin-Cotton et al. (18) & Senegal & Western & 457 & 312 & $123(39 \%)$ & $48(15 \%)$ & $141(45 \%)$ \\
\hline Ndiaye et al. (19) & Senegal & Western & 253 & 251 & $238(95 \%)$ & $13(5 \%)$ & $0(0 \%)$ \\
\hline Kassegne et al. (20)c & Togo & Western & 39 & 39 & $39(100 \%)$ & $\mathrm{N} / \mathrm{A}$ & $\mathrm{N} / \mathrm{A}$ \\
\hline Balogou et al. (21) & Togo & Western & 243 & 124 & $92(75 \%)$ & 19 (15\%) & $13(10 \%)$ \\
\hline Modi et al. (22) & South Africa & Southern & 100 & 96 & $70(73 \%)$ & $26(27 \%)$ & $0(0 \%)$ \\
\hline Bhigjee et al. (23) ${ }^{c}$ & South Africa & Southern & 33 & 33 & $\mathrm{~N} / \mathrm{A}$ & 32 (97\%) & 1 (3\%) \\
\hline Summary, mean & Africa & All & 12,020 & 3,577 & 2,097 (58.6\%) & $1,141(31.9 \%)$ & 339 (9.5\%) \\
\hline Estimate $95 \% \mathrm{Cl}$ & & & & & $57.0-60.2 \%$ & $30.4-33.5 \%$ & $8.5-10.5 \%$ \\
\hline
\end{tabular}

axcludes trauma, functional, "other causes of weakness," and polio from the denominator for non-traumatic myelopathy etiologies. Polio cases were excluded $n=248$ (17), $n=25$ (18), $n=5$ (3), and $n=1$ (5). N/A = Two studies had specific enrollment criteria with one only recruiting compressive lesions (20); and the other enrolling only non-compressive lesions (23).

'Probable myelopathy based on clinical scenario.

'Studies included in the weighted means calculation even though they had restricted inclusion criteria. Percentage totals may add up to < or >100\% due to rounding off.

(Appendix S2 in Supplementary Material). Extramedullary lesions constituted a weighted average of 58.6\% (range: 12-95\%) (Table 4). Compressive bone lesions made up the majority of cases of non-traumatic myelopathy in Africa with a weighted average of $49.1 \%$ (range: $12-83 \%$ ) while non-bone compressive lesions constituted 9.5\% (range: $0-16 \%$ ) of the lesions (Table 4). 
TABLE 4 | Extramedullary causes of non-traumatic spinal cord injury.

\begin{tabular}{|c|c|c|c|c|c|c|c|c|c|c|c|}
\hline \multirow[t]{2}{*}{ Reference } & \multirow[t]{2}{*}{ Country } & \multirow[t]{2}{*}{$\boldsymbol{N}^{*}$} & \multicolumn{7}{|c|}{ Bone lesions } & \multirow[b]{2}{*}{$\begin{array}{c}\text { Intradural } \\
\text { (extramedullary) }\end{array}$} & \multirow{2}{*}{$\begin{array}{c}\begin{array}{c}\text { Non-bone } \\
\text { lesions }\end{array} \\
\begin{array}{c}\text { Congenital } \\
\text { anomaly }\end{array}\end{array}$} \\
\hline & & & TB & $\begin{array}{c}\text { Other } \\
\text { infections }\end{array}$ & $\begin{array}{c}\text { Primary } \\
\text { neoplasm }\end{array}$ & $\begin{array}{l}\text { Metastatic } \\
\text { neoplasm }\end{array}$ & $\begin{array}{l}\text { Epidural } \\
\text { tumors }\end{array}$ & $\begin{array}{l}\text { Hematologic } \\
\text { neoplasm }\end{array}$ & $\begin{array}{l}\text { Degenerative } \\
\text { disorders }\end{array}$ & & \\
\hline Zenebe (4) & Ethiopia & 130 & $35(27 \%)$ & - & - & $14(11 \%)$ & $1(0.8 \%)$ & $6(4.6 \%)$ & $13(10 \%)$ & $7(5.4 \%)$ & - \\
\hline Zenebe et al. (9) & Ethiopia & 142 & $77(54 \%)$ & $2(1.4 \%)$ & $1(0.7 \%)$ & $11(7.7 \%)$ & - & - & $8(5.6 \%)$ & $11(7.7 \%)$ & - \\
\hline Brown (3) & Malawi & 94 & $33(35 \%)$ & $5(5 \%)$ & $2(2 \%)$ & $6(6 \%)$ & $1(1 \%)$ & $7(7 \%)$ & $5(5 \%)$ & $8(8 \%)$ & $1(1 \%)$ \\
\hline Naus et al. (10) & Malawi & 26 & - & - & - & - & - & $3(12 \%)$ & - & - & - \\
\hline Leigh (11) & Tanzania & 90 & $13(14 \%)$ & $10(11 \%)$ & - & $11(12 \%)$ & - & - & $14(16 \%)$ & - & - \\
\hline Scrimgeour (12) & Tanzania & 96 & $54(56 \%)$ & $2(2 \%)$ & $2(2 \%)$ & $8(8 \%)$ & - & - & $2(2 \%)$ & $1(1 \%)$ & - \\
\hline Parry et al. (5) & Zimbabwe & 148 & $43(29 \%)$ & $10(7 \%)$ & $14(9 \%)$ & $13(9 \%)$ & $2(1 \%)$ & - & $8(5 \%)$ & $21(14 \%)$ & $2(1 \%)$ \\
\hline Mahomed and Gelfand (13) & Zimbabwe & 65 & $21(32 \%)$ & $1(1.5 \%)$ & $1(1.5 \%)$ & $9(14 \%)$ & - & $3(4.6 \%)$ & $1(1.5 \%)$ & $5(7.7 \%)$ & $3(4.6 \%)$ \\
\hline Looti et al. (14) & Cameroon & 147 & $19(13 \%)$ & - & $5(3.4 \%)$ & 25 (17\%) & $4(2.7 \%)$ & $21(14 \%)$ & $6(4.1 \%)$ & $17(12 \%)$ & - \\
\hline Nyame (15) & Ghana & 55 & 19 (35\%) & - & - & $3(5.5 \%)$ & - & $6(11 \%)$ & $10(18 \%)$ & - & - \\
\hline Owolabi et al. (7) & Nigeria & 85 & $44(52 \%)$ & - & - & $4(4.7 \%)$ & - & $2(2.4 \%)$ & $2(2.4 \%)$ & - & - \\
\hline Ogunniyi et al. (16) & Nigeria & 108 & $26(24 \%)$ & - & _- & $8(7.4 \%)$ & _- & $6(5.6 \%)$ & $31(29 \%)$ & $2(1.9 \%)$ & - \\
\hline Osuntokun (17) & Nigeria & 1,536 & 406 (23\%) & $6(0.3 \%)$ & - & $1(0.1 \%)$ & $41(2.3 \%)$ & - & 65 (3.6\%) & $22(1.2 \%)$ & 207 (13\%) \\
\hline Jacquin-Cotton et al. (18) & Senegal & 312 & $61(18 \%)$ & $16(4.7 \%)$ & $5(1.5 \%)$ & $24(7.1 \%)$ & - & $5(1.5 \%)$ & $7(2.1 \%)$ & $5(1.5 \%)$ & - \\
\hline Ndiaye et al. (19) & Senegal & 251 & N/A & $54(22 \%)$ & $21(8.4 \%)$ & $97(39 \%)$ & 37 (15\%) & - & - & $22(8.8 \%)$ & $4(1.6 \%)$ \\
\hline Kassegne et al. (20) & Togo & 39 & $7(18 \%)$ & - & - & $17(44 \%)$ & - & - & 15 (38\%) & - & - \\
\hline Balogou et al. (21) & Togo & 124 & $17(14 \%)$ & - & $10(8.1 \%)$ & $23(19 \%)$ & - & - & 42 (34\%) & - & - \\
\hline Modi et al. (22) & South Africa & 96 & $30(31 \%)$ & - & - & 17 (18\%) & - & $6(6.1 \%)$ & $15(16 \%)$ & $2(2 \%)$ & - \\
\hline Bhigjee et al. (23) & South Africa & 33 & N/A & N/A & N/A & N/A & N/A & N/A & N/A & N/A & N/A \\
\hline Summary & & 3,577 & $905(25 \%)$ & 106 (3.1\%) & $61(1.7 \%)$ & $291(8 \%)$ & $86(2.4 \%)$ & $65(1.8 \%)$ & $244(6.8 \%)$ & $123(3.4 \%)$ & $217(6.1 \%)$ \\
\hline
\end{tabular}

Numbers represent $N(\%)$. $N^{*}$ Excludes trauma, functional, "other causes of weakness," and polio from the denominator for non-traumatic myelopathy etiologies.

aOther infections causing bone lesions included: brucellosis, histoplasmosis, and arachnoiditis.

Other causes reported included: metabolic bone diseases were reported as etiologies in four persons: $n=1(0.7 \%)(14), n=1(0.5 \%)(19)$, and $n=2(0.1 \%)(17)$. Vascular disorders were reported as etiologies in three persons: $n=1$ (1.6\%) (10) and $n=2(0.8 \%)(24)$. Kassegne et al. only included only patients with compressive bone lesions (20) while Bhigjee et al. only included patients without extramedullary lesions (23). Ndiaye et al. only enrolled compressive lesions but excluded Tb spondylitis, hence exaggerating the percentage of neoplasms in this study (19). Naus et al. only included patients without a known cause of myelopathy (10). 
Nearly 31.9\% (range: 5-97\%) had non-compressive lesions and no definitive diagnosis was identified in 9.5\% (range: 0-45\%) (Table 3). A clinical diagnosis of transverse myelopathy unclassified was the most common cause of non-compressive lesions at $4.6 \%$ (range:1-23\%) $(3,5,11,14,15)$. Typically, a diagnosis of transverse myelitis was based on lack of a compressive lesion visualized on plain radiograph and inflammatory CSF. Importantly, the underlying causes of transverse myelitis were not identified in most studies.

\section{Compressive Lesions}

The most common causes of compression were Pott's disease and tumors (Table 4). Pott's disease caused $25 \%$ of non-traumatic myelopathies (range 13-54\%) and 50\% of compressive bone lesions. The diagnosis was typically based on finding anterior wedging of the vertebral body on plain radiograph. The clinical presentation of Pott's disease in these studies differed somewhat from traditional teaching. For example, in a study by Zenebe et al. from Ethiopia, few patients presented with constitutional symptoms such as weight loss and fever that are typically associated with disseminated tuberculosis though $30 \%$ of the patients had TB at other sites as well (9). The most common presentation of Pott's disease in this study was gradual onset of weakness in the legs (92\%), vertebral deformity (88\%), and vertebral tenderness (88\%) (9). Occasionally, individuals reported sudden onset of paraplegia (7.8\%) (9).

The weighted average proportion of non-traumatic myelopathies explained by neoplasms that included primary bone neoplasms, metastatic disease, epidural tumors, hematological neoplasms, unclassified intradural, and intramedullary tumors was $18.6 \%$ (range $0-75 \%$ ). The proportion of neoplasms varied depending on the source of the study population. Neoplasms were found at frequencies as high as $49 \%$ in a neurology/neurosurgical unit in Cameroon (14), 28\% in a neurorehabilitation Centre in Zimbabwe (5) to between 13 and 25\% in most studies done on medical/neurological wards $(4,11,12,15)$. HIV prevalence may also contribute to this heterogeneity; in a South African study, HIV-uninfected individuals had a higher proportion of neoplasms than an HIV-infected group (22). Neoplasms were also more frequent in older age groups and presented at a mean age about 50 years $(9,12)$.

When differentiated from primary tumors, metastatic disease was the second most common cause of compressive bone lesions, representing a weighted average of $8.1 \%$ of nontraumatic myelopathies (range 0-44\%). Prostatic carcinoma was the most common primary tumor reported in Malawi (3), South Africa (22), and Nigeria (7) while lymphoma was the most common primary tumor in studies from Cameroon and Ghana $(14,15)$. Hepatocellular carcinoma was predominant in studies from Cameroon (14) and Ethiopia (9). The high proportions of cases of hepatocellular cancer in these regions have been attributed to the high endemicity of hepatitis B (14). Other common primary tumors identified were from the lung and breast (14).

Primary spinal and vertebral tumors were reported less frequently than metastatic disease and ranged from 0 to $20 \%$ with a weighted average of $4.6 \%(9,11)$. The most frequently reported tumors were nerve sheath tumors (Schwannoma, neurofibroma, and meningioma) and plasmocytoma $(3,14)$. Other primary tumors including lipoma, medulloblastoma, and ependymoma were rarely reported (9).

Infections other than tuberculosis that resulted in compressive lesions were less frequently reported. Spinal epidural abscess was only reported (1\%) of patients (3). Brucella spondylitis has also been described (9), presenting with a variety of presentations from myelitis to epidural abscesses to spondylitis. Two cases of Cysticercosis and one case of blastomycosis were observed in Zimbabwe (13) and one report of actinomycosis was reported in Tanzania (12).

Degenerative bone disease was infrequently reported and the weighted average was $6.8 \%$ (range: $2-38 \%$ ). Cervical spondylosis occurred more frequently in HIV-negative and older individuals more than 50 years old $(14,22)$.

\section{Non Compressive Lesions}

Intramedullary spinal cord lesions, which are non-compressive, constituted $31.9 \%$ (range 5-97\%) of non-traumatic myelopathies (Table 5). In Western Africa, the majority of intramedullary lesions were suspected to be myelopathy from an as yet undefined nutritional cause. However, in many areas, a clinical diagnosis of transverse myelopathy is the most common cause.

Intramedullary infections are presented in Table 6. Human T-Lymphotropic Virus 1 (HTLV-1) myelopathy was the most common infection identified in individuals with nontraumatic myelopathy with the following proportions $9.8 \%$ in Ethiopia (9), 4.8\% in Cameroon (14), and was lowest at $1 \%$ in South Africa (22). In studies from Ethiopia (4, 9), Tanzania (12), and Malawi (10), the diagnosis was based on a characteristic clinical presentation of insidious, slowly, and chronically progressive spastic paraparesis, without remission or acute on chronic episodes, frequently associated with paresthesia and hypoesthesia of the lower limbs, lumbago, and sphincter dysfunctions. Some studies based diagnoses on serology $(14,22)$. A study from South Africa showed 12 (36\%) of the patients had HIV/HTLV-1 coinfection (23).

Neurosyphilis was identified in three studies: $6 \%$ of patients from Malawi (3), 4\% from Tanzania (12), and $0.6 \%$ from Zimbabwe (5). The diagnosis was typically based on a positive CSF Venereal Disease Research laboratory test $(7,15)$ but also on MRI showing multiple enhancing granulomata of the cord or as a differential in patients with arachnoiditis (23).

Schistosomiasis due to Schistosoma mansoni most commonly affects the conus medullaris and cauda equine (23). There are multiple individual case reports of acute paraparesis in returning travelers from high-income countries where Schistosoma ova have refluxed into the vertebral venous system, become lodged, and generated an inflammatory reaction, mimicking transverse myelitis. Yet, the attributable burden of Schistosomiasis toward non-traumatic spinal cord disease in Sub-Saharan Africa is less clear. Studies used widely differing diagnostic criteria ranging from residing in an endemic area with no other obvious cause of myelopathy, microbiological confirmation of systemic disease, Schistosoma CSF serology to MRI findings suggestive of schistosomiasis. One study from Tanzania found that $6 \%$ of individuals 
TABLE 5 | Intramedullary causes of non-traumatic spinal cord injury.

\begin{tabular}{|c|c|c|c|c|c|c|c|c|c|}
\hline Reference & Country & $N^{*}$ & $\begin{array}{c}\text { Neoplastic } \\
\text { intramedullary }\end{array}$ & $\begin{array}{l}\text { Transverse } \\
\text { myelopathy } \\
\text { unclassified }\end{array}$ & Infection & $\begin{array}{l}\text { Inflammatory/ } \\
\text { autoimmune }\end{array}$ & $\begin{array}{l}\text { Vascular } \\
\text { disorders }\end{array}$ & Nutrition & $\begin{array}{c}\text { Miscellaneous } \\
\text { causes }\end{array}$ \\
\hline Zenebe (4) & Ethiopia & 130 & $3(2.3 \%)$ & $29(22 \%)$ & $18(14 \%)$ & - & - & $1(0.8 \%)$ & $6(2.3 \%)$ \\
\hline Zenebe et al. (9) & Ethiopia & 142 & $10(7 \%)$ & $4(2.8 \%)$ & $16(11 \%)$ & - & $2(1.4 \%)$ & - & - \\
\hline Brown (3) & Malawi & 94 & - & 7 (7.1\%) & $6(6.4 \%)$ & $1(1 \%)$ & - & $3(3 \%)$ & $6(6.1 \%)$ \\
\hline Naus et al. (10) & Malawi & 26 & - & - & $23(88 \%)$ & - & - & - & - \\
\hline Leigh (11) & Tanzania & 90 & $4(4.4 \%)$ & $6(6.7 \%)$ & $4(4.4 \%)$ & - & $4(4.4 \%)$ & - & - \\
\hline Scrimgeour (12) & Tanzania & 96 & $2(2.1 \%)$ & $1(1 \%)$ & $12(13 \%)$ & - & - & - & - \\
\hline Parry et al. (5) & Zimbabwe & 148 & - & $17(12 \%)$ & $3(2 \%)$ & - & $3(2 \%)$ & $2(1.3 \%)$ & $3(2 \%)$ \\
\hline Mahomed and Gelfand (13) & Zimbabwe & 65 & $1(1.5 \%)$ & $15(23 \%)$ & $4(6.2 \%)$ & - & - & - & $1(1.5 \%)$ \\
\hline Looti et al. (14) & Cameroon & 147 & $4(2.7 \%)$ & $6(4.1 \%)$ & $7(4.8 \%)$ & - & - & - & $1(0.7 \%)$ \\
\hline Nyame (15) & Ghana & 55 & - & 7 (13\%) & - & - & - & - & $4(7.3 \%)$ \\
\hline Owolabi et al. (7) & Nigeria & 85 & - & $15(18 \%)$ & - & - & $1(1.2 \%)$ & $3(3.5 \%)$ & 0 \\
\hline Ogunniyi et al. (16) & Nigeria & 108 & - & $9(8.3 \%)$ & $3(2.8 \%)$ & - & - & $13(12 \%)$ & $6(5.6 \%)$ \\
\hline Osuntokun (17) & Nigeria & 1,536 & - & $22(1.2 \%)$ & Polio only & 109 (6.1\%) & $6(0.3 \%)$ & 486 (27\%) & $84(4.7 \%)$ \\
\hline Jacquin-Cotton et al. (18) & Senegal & 312 & $3(0.9 \%)$ & - & $4(1.3 \%)$ & $7(2.1 \%)$ & $8(2.4 \%)$ & $1(0.3 \%)$ & 25 (7.4\%) \\
\hline Ndiaye et al. (19) & Senegal & 251 & $11(4.4 \%)$ & - & - & - & $2(0.8 \%)$ & - & - \\
\hline Kassegne et al. (20)\# & Togo & 39 & N/A & N/A & N/A & N/A & $\mathrm{N} / \mathrm{A}$ & N/A & N/A \\
\hline Balogou et al. (21) & Togo & 124 & - & $13(10.5 \%)$ & - & $2(1.6 \%)$ & - & - & $4(3.2 \%)$ \\
\hline Modi et al. (22) & South Africa & 96 & $1(1 \%)$ & $12(12 \%)$ & $4(4 \%)$ & $7(7.1 \%)$ & $1(1 \%)$ & $1(1 \%)$ & - \\
\hline Bhigjee et al. (23) & South Africa & 33 & - & $2(6.1 \%)$ & 30 (91\%) & - & - & - & - \\
\hline Summary & & 3,577 & 39 (1.1\%) & 165 (4.6\%) & 134 (3.7\%) & 126 (3.5\%) & 27 (0.8\%) & $510(14.3 \%)$ & 140 (3.9\%) \\
\hline
\end{tabular}

$N^{\star}$ Excludes trauma, functional, "other causes of weakness," and polio from the denominator for non-traumatic myelopathy etiologies.

"Only included compressive lesions.

Miscellaneous causes included motor neuron disease and syringomyelia, Nutrition causes include B12 deficiency, Konzo and tropical ataxic neuropathy. Transverse myelopathy unclassified included patients diagnosed with unclassified Transverse myelitis and HIV myelopathy. The two studies from Nigeria skewed the observations toward high burden of nutritional causes $(16,17)$.

TABLE 6 | Intramedullary infections.

\begin{tabular}{|c|c|c|c|c|c|c|c|c|}
\hline Reference & & $\boldsymbol{N}^{*}$ & Total infection & HTLV $^{\mathbf{a}}$ & Syphilis & VZV & Schistosomiasis & TB \\
\hline Zenebe (4) & Ethiopia & 130 & $18(14 \%)$ & 18 & - & - & - & - \\
\hline Zenebe et al. (9) & Ethiopia & 142 & $16(11 \%)$ & 16 & - & - & - & - \\
\hline Brown (3) & Malawi & 94 & $6(6.4 \%)$ & - & 6 & - & - & - \\
\hline Naus et al. (10) & Malawi & 26 & 23 (88\%) & 2 & - & - & 16 & 4 \\
\hline Leigh (11) & Tanzania & 90 & $4(4.4 \%)$ & - & - & - & - & 4 \\
\hline Scrimgeour (12) & Tanzania & 96 & $12(13 \%)$ & 2 & 4 & - & 6 & - \\
\hline Parry et al. (5) & Zimbabwe & 148 & $3(2 \%)$ & - & 1 & - & 1 & - \\
\hline Mahomed and Gelfand (13) & Zimbabwe & 65 & $4(6.2 \%)$ & - & 2 & - & - & - \\
\hline Looti et al. (14) & Cameroon & 147 & $7(4.8 \%)$ & 7 & - & - & - & - \\
\hline Nyame (15) & Ghana & 55 & - & - & - & - & - & - \\
\hline Owolabi et al. (7) & Nigeria & 85 & - & - & - & - & - & - \\
\hline Ogunniyi et al. (16) & Nigeria & 108 & $3(2.8 \%)$ & - & - & 1 & - & - \\
\hline Jacquin-Cotton et al. (18) & Senegal & 312 & $4(1.3 \%)$ & - & 4 & - & - & - \\
\hline Ndiaye et al. (19) & Senegal & 251 & - & - & - & - & - & - \\
\hline Kassegne et al. (20) & Togo & 39 & - & - & - & - & - & - \\
\hline Balogou et al. (21) & Togo & 124 & - & - & - & - & - & - \\
\hline Modi et al. (22) & South Africa & 96 & $4(4 \%)$ & 1 & - & 2 & - & - \\
\hline Bhigjee et al. (23) & South Africa & 33 & 30 (91\%) & 12 & 2 & 3 & 2 & 6 \\
\hline Summary & & & 134 & 58 (43\%) & 19 (14\%) & $6(4.4 \%)$ & 25 (19\%) & $14(10 \%)$ \\
\hline
\end{tabular}

$N^{\star}$ Excludes trauma, functional, "other causes of weakness," and polio from the denominator for non-traumatic myelopathy etiologies.

${ }^{a}$ All cases of tropical spastic paraparesis were categorized under HTLV.

This table presents the proportion of patients with intramedullary infections. All cases of tropical spastic paraparesis were categorized under HTLV. The denominator used in this calculation was total number of patients with infections. No intramedullary infectious etiologies were identified in five studies (7, 15, 19-21). Polio cases were excluded $n=248$ (17), $n=25$ (18), $n=5$ (3), and $n=1$ (5). The following were diagnosed in one patient with a percentage contribution of 0.7\%: Cryptococcus (10), Cytomegalovirus (CMV) (22), Klebsiella (16), Dracontiasis (16). The following were diagnosed in two patients with a percentage contribution of 1.4\% each: herpes simplex virus (HSV) (23), and cysticercosis (13). The following were diagnosed in three patients with a percentage contribution of 2.2\%: Enterovirus (23).

with non-traumatic spinal cord injury had Schistosoma eggs in urine, stool, and rectal snips (12). Schistosomiasis was mentioned in one patient in Zimbabwe (5). Nau et al. in Malawi diagnosed 16 out of 33 patients with schistosomiasis based on immunodiagnostic methods in an endemic region (10). It was diagnosed in two patients in South Africa based on MRI 
findings of the lumbosacral spine showing enhancement of the roots and a swollen conus with hyperintensity on T2-weighted MRI. One had a peripheral eosinophilia and dramatically improved on praziquantel (23).

Two studies from South Africa noted that HIV vacuolar myelopathy was found in 1-6\% of patients; diagnosis was based on low CD4+ T-cell count, high HIV viral load, MRI that showed hyper-intense signals on T2 signal intensity in the dorsal and lateral columns, and exclusion of other causes of myelopathy (22, 23). HIV myelopathy has been described in $3-16.9 \%$ of patients with myelopathy in Ethiopia and South Africa (9, 23). Other studies that did not have access to advanced imaging defined HIV myelopathy as an HIV positive patient with no other cause of myelopathy identified. In these studies, the proportion of myelopathy patients with HIV infection ranged from $14.1 \%$ in Nigeria (7), 30\% in Ethiopia (9), to $50 \%$ in South Africa (22). This mirrors the prevalence of HIV in the general population.

The other infectious causes that were identified included cytomegalovirus infection (CMV) (one patient) and varicella zoster (two patients) (22). The diagnosis of varicella myelitis was suggested by the presence of a rash. Other infections described included herpes simplex and enterovirus (23). Tuberculosis (six patients) was also described and presented as a non-specific myelopathy with CSF findings suggestive of Tuberculous meningitis or with extensive lymphadenopathy (23).

Autoimmune causes of transverse myelitis were only defined in detail in one study by Modi et al. In a population of 100 patients, 4 HIV-infected patients had acute demyelinating encephalomyelitis diagnosis based on spine and Brain MRI, one had systemic lupus erythematosus, and two HIV-infected patients had presumed neuromyelitis optica based on imaging and CSF findings only. In the same study, four HIV-negative patients were diagnosed with idiopathic transverse myelitis (22).

Vascular, metabolic, nutritional, and other causes for non-traumatic spinal cord injury were relatively rare and no consistent testing was performed in most studies. Spinal cord infarction was confirmed in one patient from South Africa (22), two post-partum mothers in Zimbabwe (5), one in Nigeria (7), one in Ethiopia (9), and in $4 \%$ of the patients in Tanzania (11). Metabolic conditions were not reported in most of these studies but potential etiologies include Konzo, neurolathryism, and B12 deficiency. There is literature about Konzo due to cassava consumption in Mozambique, Tanzania, Democratic Republic of the Congo, and Central African Republic (25-30). Konzo is diagnosed by its epidemiologic pattern, nutritional habits in addition to serum and urine thiocyanate concentrations (27). Neurolarythrism due to ingestion of Lathyrus sativus plant has been described in Ethiopia (28, 31-33). Vitamin B12 deficiency has been described in a $1-3 \%$ of the patients in South Africa, Cameroon, Nigeria, and Malawi $(3,5,7,14,22)$. There is a reported suspected nutritional causes of myelopathy in large numbers of patients from Nigeria $(16,17)$.

\section{Other Conditions}

A condition classified as miscellaneous causes like motor neuron diseases and syringomyelia constituted only a weighted average of $3.9 \%$ range $0-7.4 \%$ of the patients $(3,5,15)$.

\section{Proposed Diagnostic Algorithm for Non-Traumatic Spinal Cord Injury in Resource-Limited Settings}

As we reviewed the results of our systematic review in detail, we noted several findings with important implications for a diagnostic algorithm:

1. Age: younger patients are more likely to have an unknown cause or tuberculosis as the cause of their myelopathy while older patients are more likely to have metastatic tumors or degenerative conditions (Figure 3).

2. HIV: HIV-infected patients tend to be younger than HIVnegative patients and are more likely to have infectious etiologies $(22,23)$.

3. Availability of diagnostics: plain radiographs of the spine, HIV antibody testing, erythrocyte sedimentation rate (ESR), and full hemogram were widely available and generally affordable for patients. Alpha fetal protein and prostatic-specific antigen were also frequently available.

4. Role of ESR: the role of ESR is debated but has been found consistently raised in Potts disease $(4,16)$.

5. Most common etiologies: Pott's Disease and metastatic disease are the most common causes of compressive lesions and transverse myelitis of unclear etiology is the most common cause of non-compressive lesions.

6. Cost of diagnostic modalities: the average cost of an MRI in Uganda is 200 USD in a country with a GDP of 714.6 USD and the total expenditure on health as \% for GDP (2014) was 7.2\%. The health expenditure per capita was 52 USD well below what would be required to investigate such a patient.

7. Availability of treatment: the available treatments include. Anti-tuberculosis medications, Vitamin B12 supplementation, steroids, radiotherapy, anti-cancer drugs, and surgical resection.

We propose the following algorithm presented in Figure 2.

\section{Step 1}

Screening

History and Examination. Spinal cord disorders may present with any combination of the signs and symptoms below:

a. Motor deficits: weakness in the limbs, may be symmetric or asymmetric; typically involves both legs, or both legs and both arms together. This is usually accompanied by increased tone, brisk reflexes, clonus, or present Babinski sign (up going toe).

b. Sensory deficits: lack of sensation (numbness to touch, temperature, and for advanced practitioners to vibration or position sense) or abnormal sensations (parasthesias/tingling). Like the motor deficits, the sensory deficits may be symmetric or asymmetric; typically involves both legs, or both legs and both arms together. There may be a distinct level on the trunk below which the patient does not have sensation.

c. Autonomic nervous system deficits: there may be urinary retention with overflow incontinence, fecal constipation or 


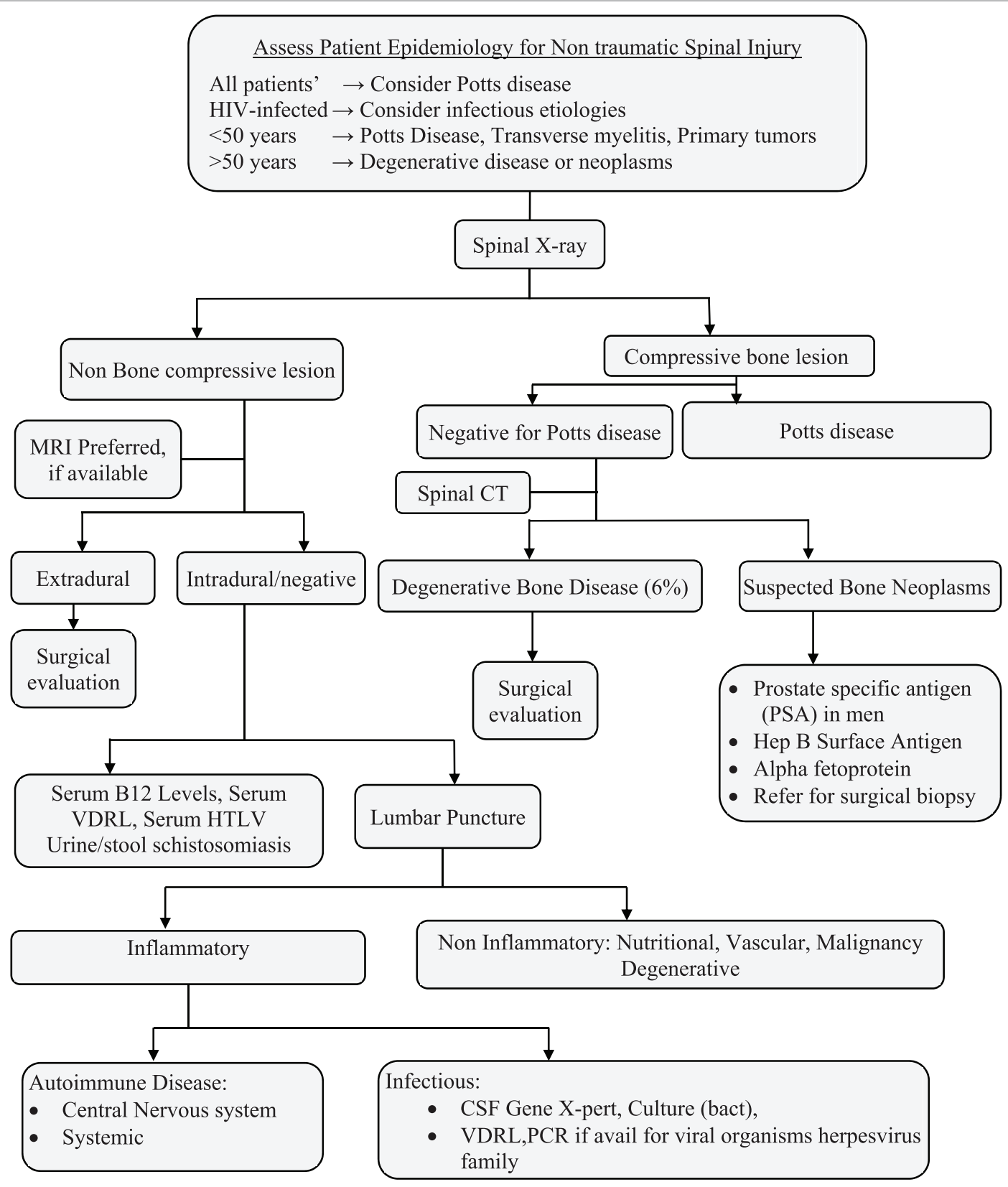

FIGURE 2 | Proposed diagnostic algorithm for non-traumatic spinal cord injury. Proposed diagnostic Algorithm of a patient who presents with non-traumatic myelopathy from the first contact with the health system in the sub-Saharan Africa. CT, computerized tomography; MRI, magnetic resonance imaging; VDRL, Venereal Disease Research Laboratory; PCR, polymerase chain reaction; CSF, cerebral spinal fluid; Hep B, hepatitis B antigen.

incontinence, and erectile dysfunction. In very severe cases, there may be paralysis of the muscles of respiration or orthostatic hypotension.

\section{Step 2}

\section{Localize the Lesion}

It is of the utmost importance to roughly localize the lesion, so that appropriate imaging studies can be ordered. Because damage to the spinal cord, may be patchy, our clinical examination can only show us the lowest possible spinal level affected. For example, if someone has weakness and sensory loss in both legs, the lesion could be in the lumbar, thoracic, or cervical cord. By contrast, if someone has both arm and leg weakness and sensory loss, the lesion can ONLY be in the cervical cord or above.

1. Lumbar/thoracic/cervical: only legs are affected; may have no sensory level on the trunk.

2. Thoracic/cervical: legs are affected, may have a sensory level on the trunk.

3. Cervical: arms and legs are affected. 


\section{AGE VERSUS DIAGNOSIS}

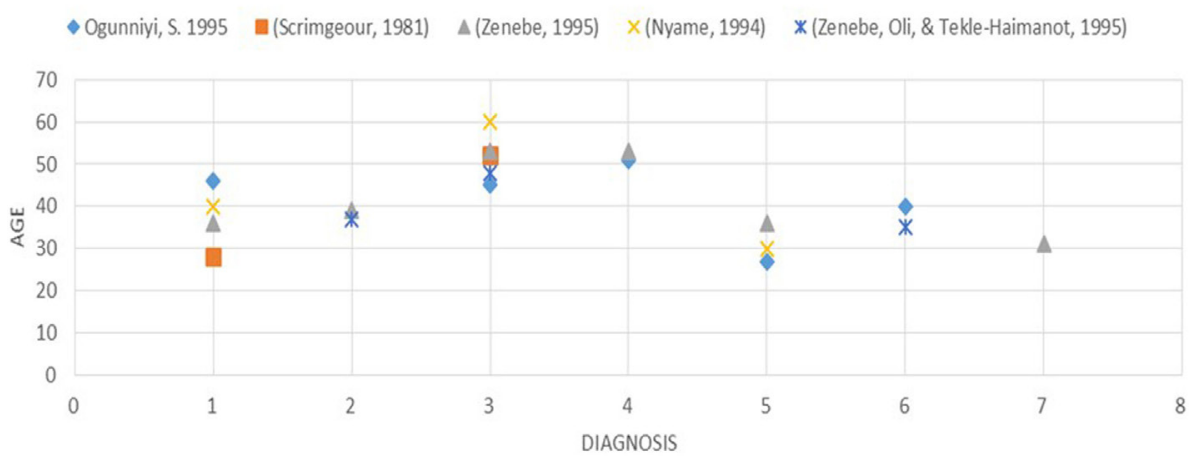

FIGURE 3 | The graph shows age versus diagnosis: 1, TB; 2, primary tumors; 3, metastatic disease; 4, degenerative conditions; 5 , TM; 6, HIV myelopathy.

\section{Step 3}

To further evaluate the patient, please refer to Figure 2.

\section{DISCUSSION}

In most of the studies, diagnosis was based on clinical evaluation and on plain radiograph and only in few studies advanced imaging in form of CT/MRI done. However, plain X-rays are limited in the diagnosis of non-compressive myelopathy and other infective etiologies with the exception of Potts disease. Compressive myelopathy of bony lesion was most common etiology and transverse myelopathy of unclassified group were common in non-compressive lesion group.

Pott's disease is one of the most common causes of non-traumatic myelopathy in sub-Saharan Africa. Tumors, both primary and metastatic, are also common though this may be somewhat biased as several studies were taken from neurosurgical case series (3). Nonetheless, a specific etiology cannot be identified in a large proportion of individuals with non-compressive lesions though most studies had limited investigative capacity. Vascular anomaly of spinal cord cases was missing. In the group of noncompressive lesion, evaluation for vasculitis to be considered. To improve care for individuals with non-traumatic myelopathy in resource-limited settings, there is an urgent need to increase availability of laboratory tests that can identify treatable causes of myelopathy, such as neurosyphilis, HTLV, HSV, VZV, and B12 deficiency. Additional research to better understand the causes of non-traumatic myelopathy in sub-Saharan Africa, especially the treatable causes, is critical to improve care and outcomes from this disorder.

A simple algorithm has the potential to more efficiently triage and evaluate patients in low-resource settings and can assist primary health care providers and non-neurologist physicians in the management of these patients. To improve capacity for the care of patients with non-traumatic myelopathy, it will also be essential to train primary health care providers in neurology, increase post-graduate neurology training opportunities, and increase availability and affordability of MRI and laboratory tests. Raising awareness so that patients present for medical care for non-traumatic myelopathies more quickly will also be important to improve outcomes from this disorder.

\section{AUTHOR CONTRIBUTIONS}

AKM participated in the study conception, design, data aquisition, data analysis, drafting, revision, final approval, and agreement. DM participated in the study design, data aquisition, revision, final approval, and agreement. PB participated in the study conception, design, revision, final approval, and agreement. EK participated in the study conception, revision, final approval, and agreement. $\mathrm{PB}$ participated in the data aquisition, data analysis, drafting, revision, final approval, and agreement. DB participated in the study conception, design, data analysis, drafting, revision, final approval, and agreement. ALM participated in the study design, data aquisition, data analysis, drafting, revision, final approval, and agreement.

\section{ACKNOWLEDGMENTS}

This work was supported in part by the NIH Fogarty International Center (R25TW009345), NIH grant K24 AI096925, and the Division of Infectious Diseases and International Medicine at the University of Minnesota Dr. Meyer was supported by Fogarty International Center of the National Institutes of Health [K01TW008764]. The authors thank Mr. Mark Gentry at the Yale University Library.

\section{SUPPLEMENTARY MATERIAL}

The Supplementary Material for this article can be found online at http://www.frontiersin.org/article/10.3389/fneur.2017.00618/ full\#supplementary-material. 


\section{REFERENCES}

1. New PW, Cripps RA, Bonne Lee B. Global maps of non-traumatic spinal cord injury epidemiology: towards a living data repository. Spinal Cord (2014) 52(2):97-109. doi:10.1038/sc.2012.165

2. Draulans N, Kiekens C, Roels E, Peers K. Etiology of spinal cord injuries in Sub-Saharan Africa. Spinal Cord (2011) 49(12):1148-54. doi:10.1038/ sc. 2011.93

3. Brown KG. Non-traumatic paraplegia in sub-Saharan Africa. East Afr Med J (1979) 56(7):300-10.

4. Zenebe G. Myelopathies in Ethiopia. East Afr Med J (1995) 72(1):42-5.

5. Parry O, Bhebhe E, Levy LF. Non-traumatic paraplegia [correction of paraplegis] in a Zimbabwean population - a retrospective survey. Cent Afr J Med (1999) 45(5):114-9.

6. Kawu AA, Olawepo A, Salami AO, Kuranga SA, Abdulhameed S, Esenwah VC. A cost analysis of conservative management of spinal cordinjured patients in Nigeria. Spinal Cord (2011) 49(11):1134-7. doi:10.1038/ sc. 2011.69

7. Owolabi LF, Ibrahim A, Samaila AA. Profile and outcome of non-traumatic paraplegia in Kano, northwestern Nigeria. Ann Afr Med (2011) 10(2):86-90. doi:10.4103/1596-3519.82062

8. Moher D, Liberati A, Tetzlaff J, Altman DG. Preferred reporting items for systematic reviews and meta-analyses: the PRISMA statement. PLoS Med (2009) 6(7):e1000097. doi:10.1371/journal.pmed.1000097

9. Zenebe G, Oli K, Tekle-Haimanot R. Paraplegia at the Tikur Anbessa Teaching Hospital: a seven year retrospective study of 164 cases. Ethiop Med J (1995) 33(1):7-13.

10. Naus CWA, Chipwete J, Visser LG, Zijlstra EE, Van Lieshout L. The contribution made by Schistosoma infection to non-traumatic disorders of the spinal cord in Malawi. Ann Trop Med Parasitol (2003) 97(7):711-21. doi: $10.1179 / 000349803225002363$

11. Leigh PN. Non-traumatic quadriplegia and paraplegia in Dar es Salaam, Tanzania. East Afr Med J (1986) 63(5):322-33.

12. Scrimgeour EM. Non-traumatic paraplegia in northern Tanzania. Br Med J (1981) 283(6297):975-8. doi:10.1136/bmj.283.6297.975

13. Mahomed K, Gelfand M. A retrospective study on the aetiology of paraplegia in Rhodesian Africans. Cent Afr J Med (1975) 21(12):251-4.

14. Looti AZL, Kengne AP, Djientcheu VDP, Kuate CT, Njamnshi AK. Patterns of non-traumatic myelopathies in Yaounde (Cameroon): a hospital based study. J Neurol Neurosurg Psychiatry (2010) 81(7):768-70. doi:10.1136/ jnnp.2009.177519

15. Nyame PK. An aetiological survey of paraplegia in Accra. East Afr Med J (1994) 71(8):527-30.

16. Ogunniyi A, Shokunbi MT, Oluwole OS, Adeyinka A, Malomo A, Adebiyi AA. Non-traumatic spinal cord diseases in Ibadan, Nigeria: aetiology and prognostic factors. Cent Afr J Med (1995) 41(2):50-4.

17. Osuntokun BO. The pattern of neurological illness in tropical Africa. Experience at Ibadan, Nigeria. J Neurol Sci (1971) 12(4):417-42. doi:10.1016/ 0022-510X(71)90110-9

18. Jacquin-Cotton L, Dumas M, Girard PL. [Paraplegia in Senegal]. Bull Soc Med Afr Noire Lang Fr (1970) 15(2):206-20.

19. Ndiaye IP, Ndiaye MM, Gueye M, Mauferon JB, Kone S, Gueye L. [Etiological aspects of non-tubercular spinal cord compression in Senegal (report of 253 cases)]. Dakar Med (1989) 34(1-4):64-7.
20. Kassegne I, Sakiye K, Kanassoua K, Beketi AK, Badiane SB, Balogou KA. [Management of spinal cord compression in Togo]. Medecine et sante tropicales (2013) 23(2):206-10. doi:10.1684/mst.2013.0177

21. Balogou AA, Grunitzky EK, Kpade C, Belo M. [Non-traumatic paraplegia at the campus teaching hospital of Lome. Report of 243 cases]. Tunis Med (2002) 80(1):33-6.

22. Modi G, Ranchhod J, Hari K, Mochan A, Modi M. Non-traumatic myelopathy at the Chris Hani Baragwanath Hospital, South Africa - the influence of HIV. QJM (2011) 104(8):697-703. doi:10.1093/qjmed/hcr038

23. Bhigjee AI, Madurai S, Bill PL, Patel V, Corr P, Naidoo MN, et al. Spectrum of myelopathies in HIV seropositive South African patients. Neurology (2001) 57(2):348-51. doi:10.1212/WNL.57.2.348

24. New PW, Marshall R. International Spinal Cord Injury Data Sets for non-traumatic spinal cord injury. Spinal Cord (2014) 52(2):123-32. doi:10.1038/sc.2012.160

25. Oluwole OS, Onabolu AO, Link H, Rosling H. Persistence of tropical ataxic neuropathy in a Nigerian community. J Neurol Neurosurg Psychiatry (2000) 69(1):96-101. doi:10.1136/jnnp.69.1.96

26. Ciglenecki I, Eyema R, Kabanda C, Taafo F, Mekaoui H, Urbaniak V. Konzo outbreak among refugees from Central African Republic in Eastern region, Cameroon. Food Chem Toxicol (2011) 49(3):579-82. doi:10.1016/j. fct.2010.05.081

27. Cliff J, Muquingue H, Nhassico D, Nzwalo H, Bradbury JH. Konzo and continuing cyanide intoxication from cassava in Mozambique. Food Chem Toxicol (2011) 49(3):631-5. doi:10.1016/j.fct.2010.06.056

28. Ngudi DD, Kuo YH, Van Montagu M, Lambein F. Research on motor neuron diseases konzo and neurolathyrism: trends from 1990 to 2010. PLoS Negl Trop Dis (2012) 6(7):e1759. doi:10.1371/journal.pntd.0001759

29. Banea JP, Bradbury JH, Mandombi C, Nahimana D, Denton IC, Kuwa N, et al. Control of konzo by detoxification of cassava flour in three villages in the Democratic Republic of Congo. Food Chem Toxicol (2013) 60:506-13. doi:10.1016/j.fct.2013.08.012

30. Oluwole OS. Cyclical konzo epidemics and climate variability. Ann Neurol (2015) 77(3):371-80. doi:10.1002/ana.24334

31. Getahun H, Lambein F, Vanhoorne M, Van der Stuyft P. Pattern and associated factors of the neurolathyrism epidemic in Ethiopia. Trop Med Int Health (2002) 7(2):118-24. doi:10.1046/j.1365-3156.2002.00836.x

32. Fikre A, Van Moorhem M, Ahmed S, Lambein F, Gheysen G. Studies on neurolathyrism in Ethiopia: dietary habits, perception of risks and prevention. Food Chem Toxicol (2011) 49(3):678-84. doi:10.1016/j.fct.2010.09.035

33. Woldeamanuel YW, Hassan A, Zenebe G. Neurolathyrism: two Ethiopian case reports and review of the literature. J Neurol (2012) 259(7):1263-8. doi:10.1007/s00415-011-6306-4

Conflict of Interest Statement: The authors declare that the research was conducted in the absence of any commercial or financial relationships that could be construed as a potential conflict of interest.

Copyright (c) 2017 Musubire, Meya, Bohjanen, Katabira, Barasukana, Boulware and Meyer. This is an open-access article distributed under the terms of the Creative Commons Attribution License (CC BY). The use, distribution or reproduction in other forums is permitted, provided the original author(s) or licensor are credited and that the original publication in this journal is cited, in accordance with accepted academic practice. No use, distribution or reproduction is permitted which does not comply with these terms. 